\title{
How much water can bioretention retain, and where does it go?
}

\author{
Sylvie Spraakman ${ }^{1}$, Jean-Luc Martel ${ }^{2}$, and Jennifer Drake ${ }^{1}$ \\ ${ }^{1}$ University of Toronto \\ ${ }^{2}$ Ecole de technologie superieure
}

September 25, 2021

\begin{abstract}
Bioretention is a type of green stormwater infrastructure for the urban environment that mimics a natural hydrologic system by reducing peak flows and runoff volumes and encouraging infiltration and evapotranspiration. This study examines the complete water balance of a bioretention system located in Vaughan, Ontario, Canada, between 2018 and 2019. The water balance was further broken down by event size, where the event size was determined by rainfall frequency analysis. Recharge was the largest component of the water balance overall ( $86 \%$ of inflow), as well as by event size. Evapotranspiration was the next largest water balance component ( $7 \%$ of inflow overall), and was a significant component of inflow (21\%) when considering only small events (50\% probability of recurrence). Evapotranspiration is a slow but consistent process, averaging $2.3 \mathrm{~mm} /$ day overall and $2.9 \mathrm{~mm}$ /day during the growing season. Climate change is likely to bring more wet days and higher temperatures, which will impact the bioretention water balance by increasing evapotranspiration and inflow. Design standards for retention targets should be updated based on the most recent rainfall frequency analyses to adjust for changing climate conditions.
\end{abstract}

\section{Hosted file}

SpraakmanMartelDrake_final.docx available at https://authorea.com/users/436829/articles/ 538881-how-much-water-can-bioretention-retain-and-where-does-it-go 

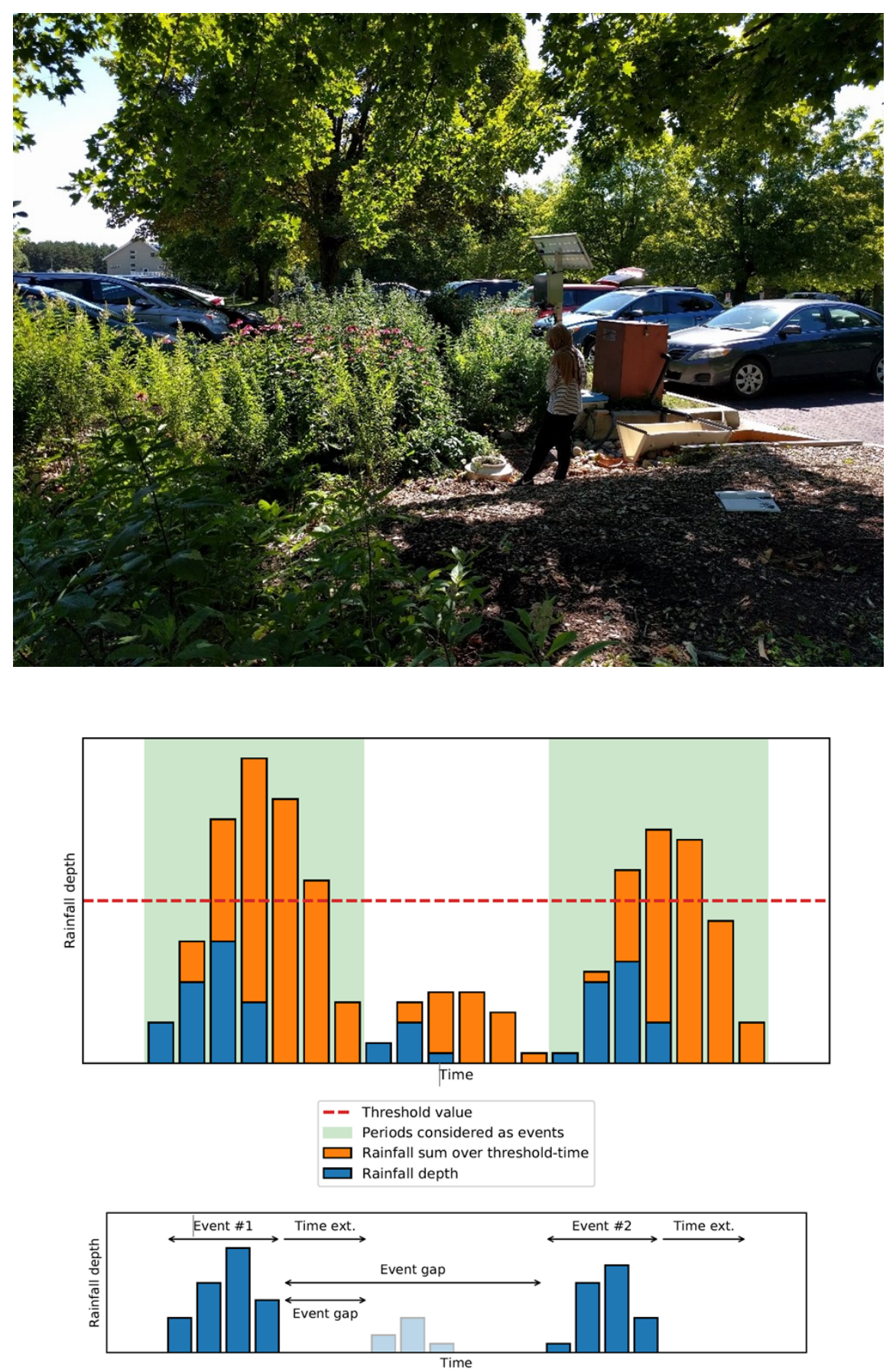


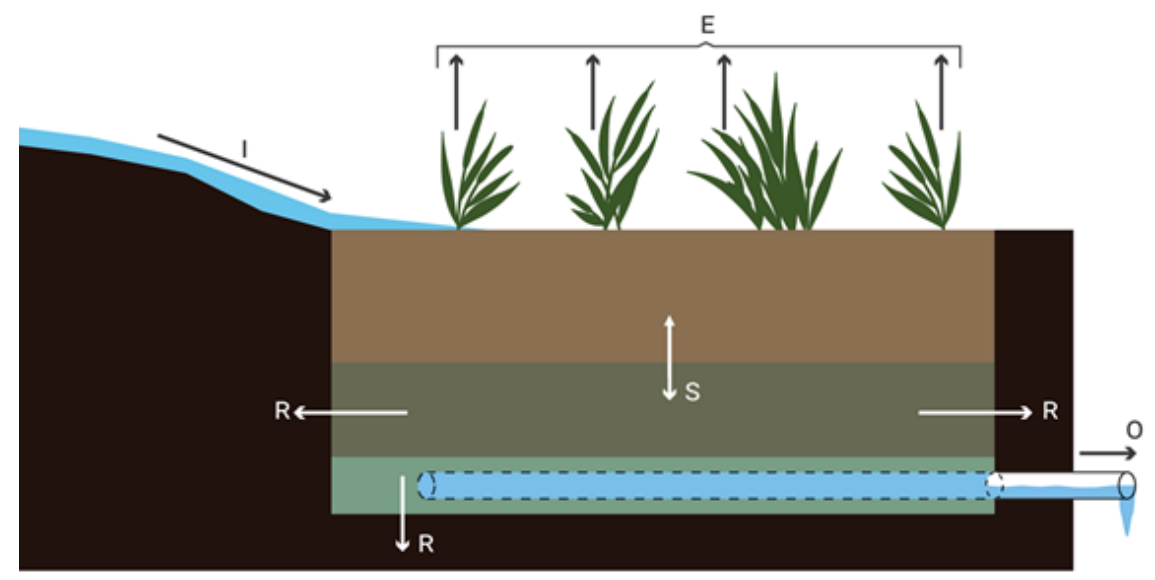

Rain gauge: hy039

rainfall events with more than $1 \mathrm{~mm}$ (466 events - 2008 to 2020)

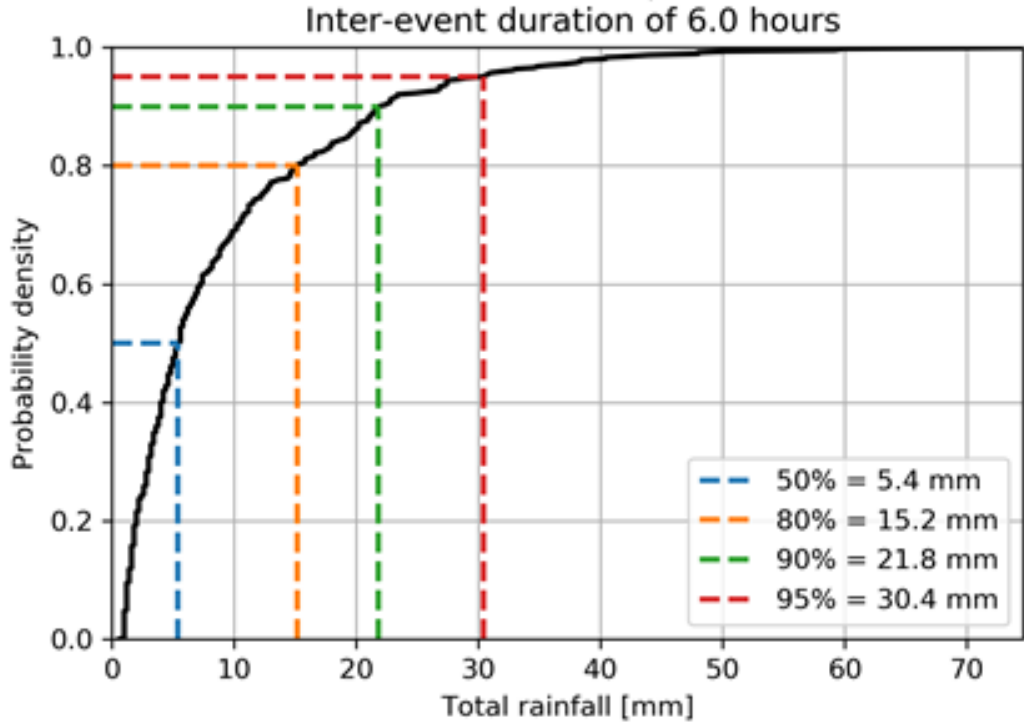


(a)

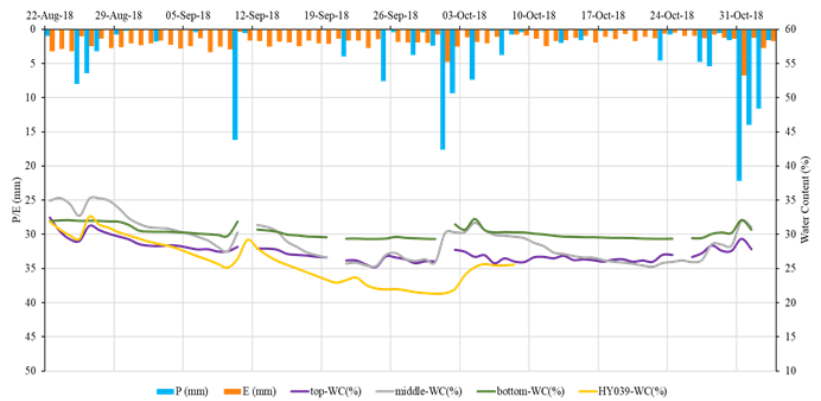

(b)

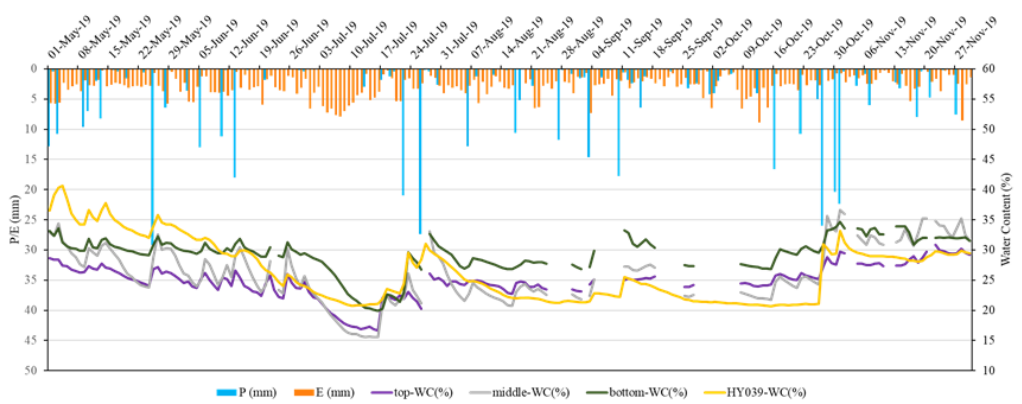

(a) Full monitoring period

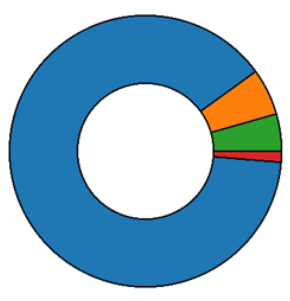

(c) Summer (June-August 2019)

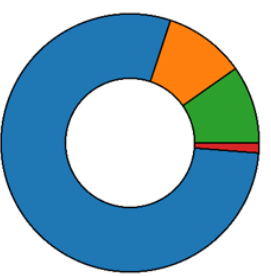

(b) Spring (May 2019)

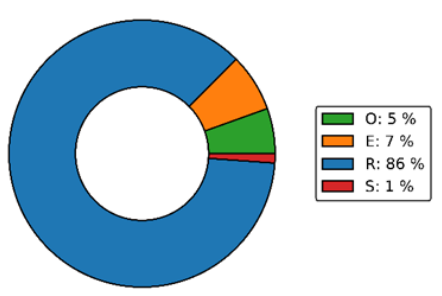

(d) Fall (September- November 2018 \& 2019)

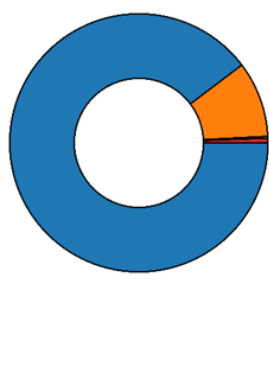

0: $1 \%$

R: $90 \%$

s: $-1 \%$ 

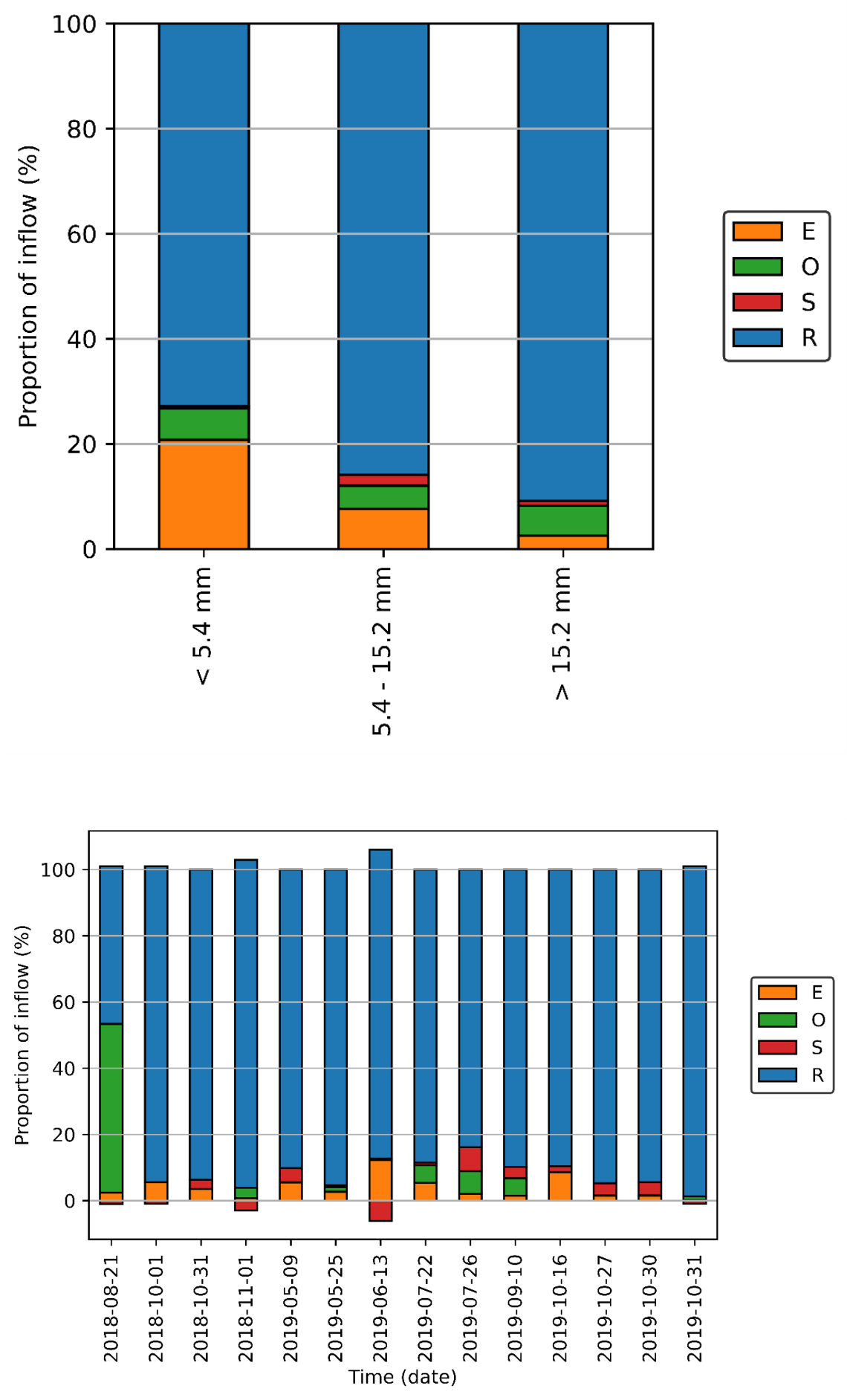

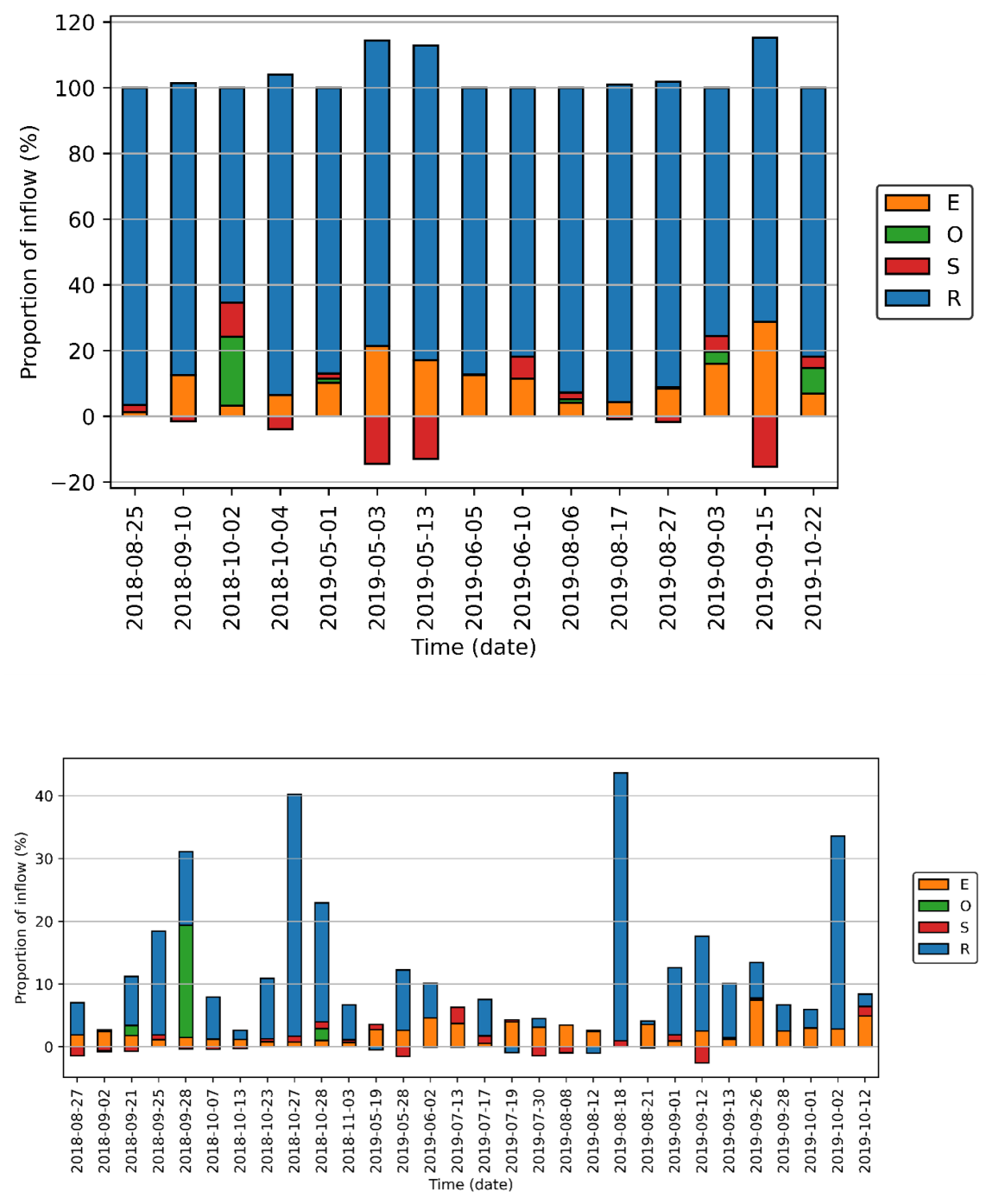
(a)

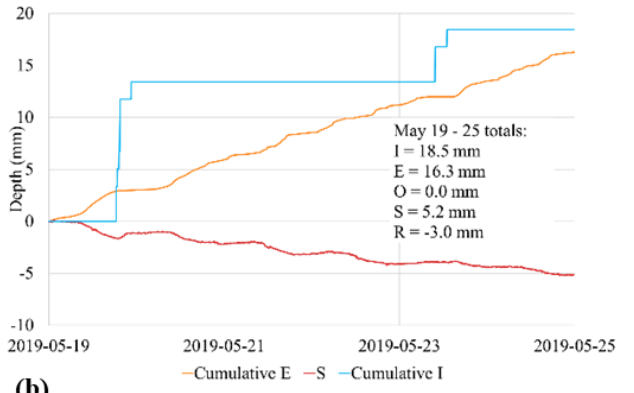

(b)

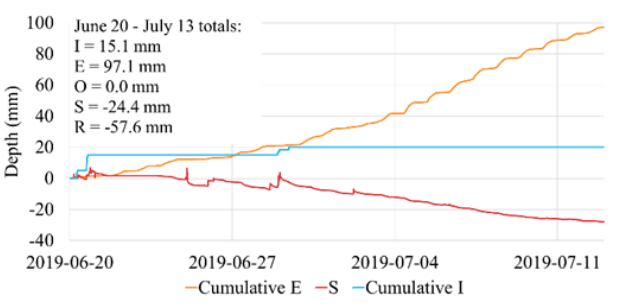

\section{Hosted file}

Tables.docx available at https://authorea.com/users/436829/articles/538881-how-much-watercan-bioretention-retain-and-where-does-it-go 